\title{
Cimetidine and gastric cancer: preliminary report from post-marketing surveillance study
}

\author{
D G COLIN-JONES, M J S LANGMAN, D H LAWSON, M P VESSEY
}

\begin{abstract}
Widespread publicity has been given to the possibility that cimetidine treatment might cause gastric cancer. Preliminary data are given from a post-marketing surveillance study in four centres. A total of 9940 patients taking the drug entered the study and 9504 were observed for at least a year. Seventy-four cases of gastric cancer were identified in those taking cimetidine, but 23 of these were diagnosed before the use of the drug and 29 others with advanced malignancy had received cimetidine within the previous six months only. Ten of the remaining 22 had gastric cancer diagnosed within a year of starting treatment, and 12 after more than a year; only four of the total group had histologically "early" cancer. The occurrence of gastric cancer a long time after starting cimetidine treatment cannot be explained in every case, but it is noteworthy that in a control group (which is not directly comparable) gastric cancer was observed in eight patients.
\end{abstract}

The hypothesis that cimetidine treatment predisposes to gastric cancer cannot be excluded by our findings: in our view, however, they do not support such an association.

\section{Introduction}

In 1978 we began a post-marketing surveillance study to detect possible adverse effects of cimetidine treatment. We collected information in four centres (Glasgow, Nottingham, Oxford, and Portsmouth) over a period of at least 12 months on patients who had been prescribed cimetidine and on a control group. Details of the methods used in the investigation have been outlined elsewhere. ${ }^{1}$

\section{Subjects and methods}

Each patient given a prescription for cimetidine by a general practitioner collaborating in the study was identified through the Prescription Pricing Bureau (Nottingham) or through the local pharmacist who dispensed the prescription (Glasgow, Oxford, Portsmouth). After the patient had been identified, an initial visit to the doctor's practice was made and details of age, sex, and indication for the treatment were recorded. At the same visit a control was recruited for each patient taking cimetidine by selecting the next patient in the practice file of the same sex, whose age was in the same

Queen Alexandra Hospital, Portsmouth PO6 3LY

D G COLIN-JONES, MD, FRCP, consultant physician

University Department of Therapeutics, City Hospital, Nottingham NG5 1PB

M J S LANGMAN, MD, FRCP, professor

Department of Clinical Pharmacology, Royal Infirmary, Glasgow G4 OSF

D H LAWSON, MD, FRCP, professor

Department of Community Medicine and General Practice, University of Oxford, Radcliffe Infirmary, Oxford

M P VESSEY, MD, FRCP, professor decade, who had attended the practice within the previous 12 months, and who was not known to have taken cimetidine. It was sometimes difficult to find a suitable control-for example, for elderly patients -and in certain surgeries it was impracticable for administrative reasons. After about 15 months the practice was visited again, the patients' notes were examined, and events requiring outpatient or inpatient consultant advice were recorded for both the taker and the control together with details of deaths and adverse reactions noted by the general practitioner. The recording of prescription information was as far as possible continuous, thus providing a reasonable estimate of exposure to cimetidine.

Recently there has been concern about a possible association between cimetidine and gastric cancer. Accordingly, we decided to review the cases of gastric cancer that occurred in our study, though it was obvious that interpretation of the data would present considerable difficulties. Hospital records, necropsy reports, death certificates, and general practitioner records were examined and in most cases the information obtained was comprehensive.

\section{Results}

Details were available after not less than one year of follow-up for 9504 recipients of cimetidine and 8994 controls (table I). The average

TABLE I-Numbers of patients and controls recruited and reviewed (to 31 December 1981) in post-marketing surveillance of cimetidine

\begin{tabular}{lcccccc}
\hline & \multicolumn{2}{c}{ Patients taking cimetidine } & & \multicolumn{2}{c}{ Controls } \\
\cline { 2 - 3 } \cline { 5 - 6 } & Recruited & Reviewed & & Recruited & Reviewed \\
\hline Glasgow & 2550 & 2507 & & 2010 & 2000 \\
Nottingham & 2083 & 1850 & & 2070 & 1850 \\
Oxford & 2654 & 2641 & & 2647 & 2628 \\
Portsmouth & 2653 & 2506 & & 2639 & 2516 \\
\hline Total & 9940 & 9504 & & 9366 & 8994 \\
\hline
\end{tabular}

age of the recipients and controls at entry to the study was 55 years for women and 50 years for men, with men comprising $63 \%$ of each group. Seventy-four $(0.78 \%)$ recipients of cimetidine are known to have suffered a gastric carcinoma: 23 of these cases were diagnosed before the start of cimetidine treatment and have been excluded from further review. The remaining 51 were diagnosed after administration of the drug (figure): four of these cases occurred before the start of the survey and eight were diagnosed after the end of the 12-month study period. Thus 39 cases were diagnosed during the $12-$ month study period. Gastric carcinoma was diagnosed in eight $(0.09 \%)$ controls; three of these cases were diagnosed during the study period.

Gastric cancer diagnosed within six months of first cimetidine useTwenty-nine cases of gastric carcinoma were diagnosed within six months of starting treatment. All 29 patients had advanced cancer (a large primary tumour, metastases, or both at the time of diagnosis). A total of 24 cases were diagnosed within three months of starting treatment. It seems likely that in every instance cimetidine was used to treat symptoms of an undiagnosed malignancy.

Gastric cancer diagnosed six months or more after first cimetidine use -Twenty-two cases were diagnosed six months or more after starting cimetidine treatment. Ten of these 22 cases were diagnosed within 12 months of starting cimetidine and 12 more than 12 months later. Table II shows the duration of cimetidine treatment and brief clinical details before the diagnosis of cancer. Four patients had an early cancer (local invasion limited to mucosa and submucosa ${ }^{2}$ ), one of whom (case 4252) had a lymph node metastasis at the time of surgery. Case 2522 had a tumour arising adjacent to a chronic gastric ulcer in the body of the stomach: no glands were affected. Case 1723 had a 20-year history of dyspepsia with a localised adenocarcinoma in the 


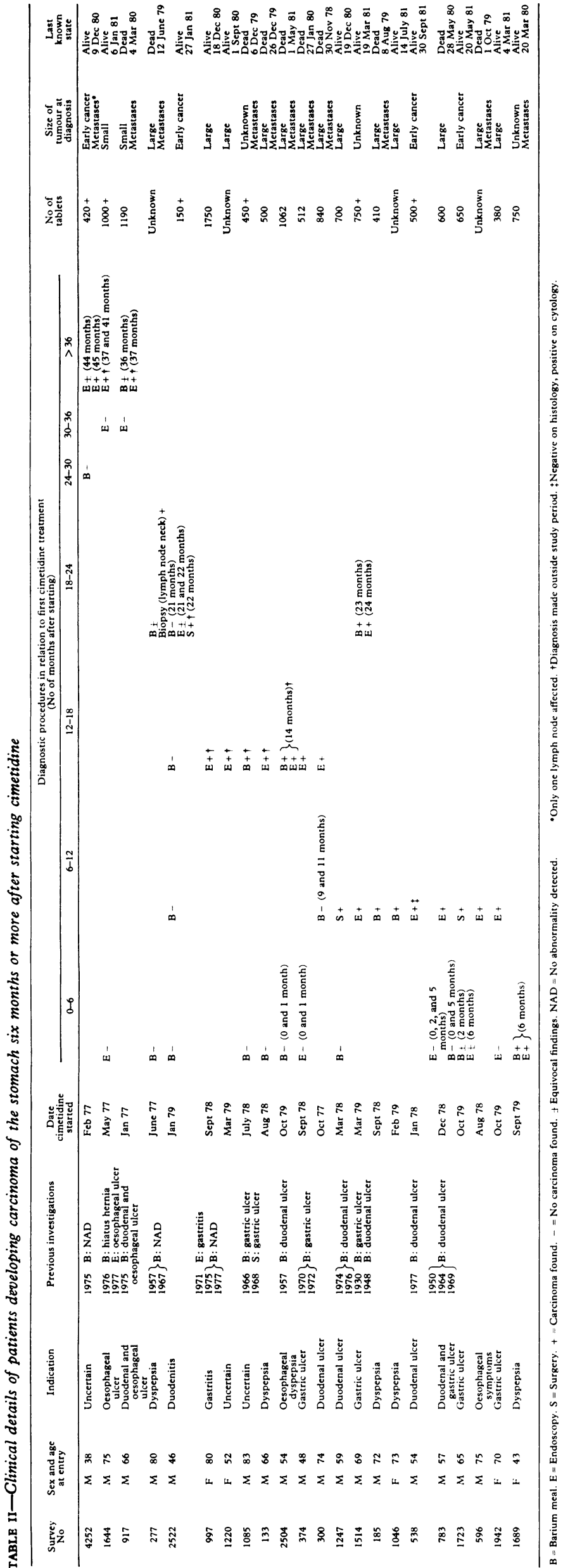

body of the stomach. Case 538 had a prepyloric tumour detected by cytology with a history of chronic duodenal ulceration diagnosed one

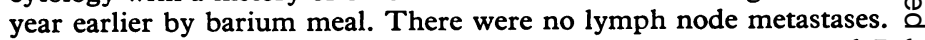
These four cases were diagnosed as having cancer $44,21,7$, and $7 \stackrel{C}{C}$ months respectively after starting cimetidine.

The total number of tablets taken varied widely and did not appear $\overline{\bar{J}}$ to be related to development of gastric cancer.

Gastric cancer in controls-Eight of the 8994 control subjects $\mathbb{\infty}$ developed gastric cancer. In three the carcinoma had been diagnosed m before entry into the study, surgery having been undertaken in two 0 of the patients seven and 62 months previously. In three patients the

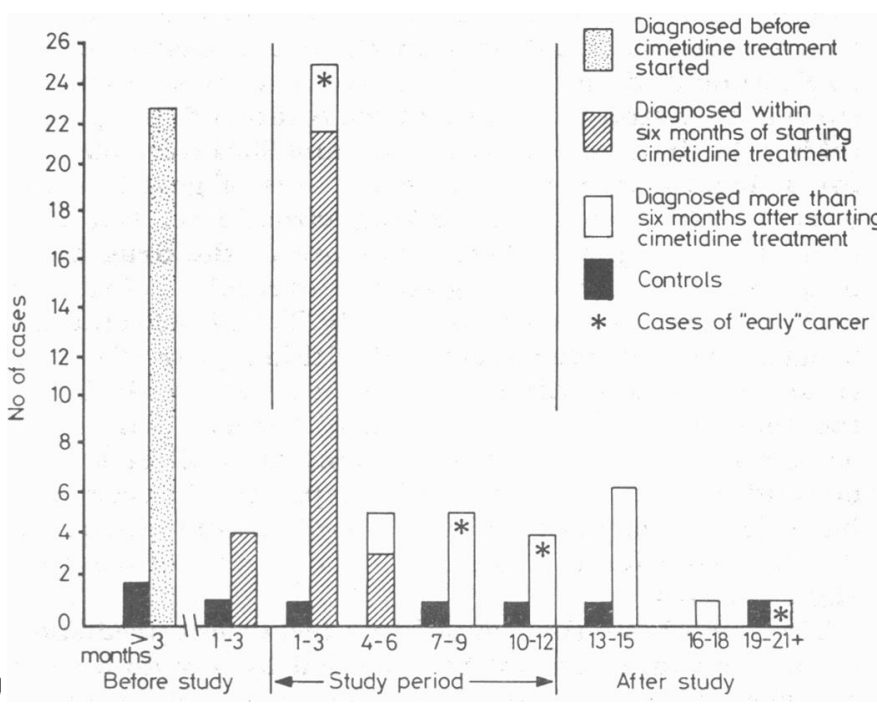

Diagnosis of carcinoma of stomach in relation to cimetidine treatment and study period.

diagnosis was made during the study period, and in one more patient the diagnosis was made three days outside the study period: in these four patients the tumour was advanced at the time of diagnosis. In two cases (one diagnosed in the study period and one after) there were multiple metastases that were presumed on clinical grounds to have $\mathbb{D}$ come from the stomach but no further information was available.

\section{Discussion}

The information we present was compiled because of concern that cimetidine treatment may predispose to the development of gastric cancer. There are inevitable difficulties in assessing the data. Firstly, cimetidine treatment in some patients was started without full prior clinical assessment, so that symptoms $ᄋ$ of malignancy may have occasioned treatment. Secondly, initial assessment when undertaken may have mistakenly suggested the $\stackrel{5}{\supset}$ presence of a benign lesion. Thirdly, gastric cancer is common, $\mathbb{N}$ having an incidence that increases progressively with age- $>$ recent figures in England and Wales would vary from about 20 을 per 100000 at ages 50 to 54 years to about 170 per 100000 at ages 70 to 74 years in men. Any group of 10000 people would N therefore be expected to include several cases of gastric cancer $\omega$ each year, as is illustrated by the experience of our control group.

The length of time that a malignant lesion can exist in the stomach without causing symptoms is unknown, but data from Japan, where some individuals have been screened regularly by double-contrast radiology, suggest that some cases of cancer may remain superficial for three or four years. ${ }^{3}$

Twenty-nine of the 51 patients we describe had advanced $\frac{\rho}{\oplus}$ tumours and had received cimetidine for no more than six $\frac{\varrho}{\sigma}$ months at the time of diagnosis of cancer; in these patients symptoms due to malignant lesions must have led to treatment. 8 The further 10 in whom cancer was diagnosed from six months? to a year after the start of cimetidine treatment are also likely 
to have had treatment for a malignant lesion, though it should be noted that initial endoscopic or radiological examinations gave negative results in four and that two of them had early cancer.

The findings in the remaining 12 , in whom cancer was diagnosed more than 12 months after starting treatment, are the most difficult to assess. Two had early cancer, and three had cancer diagnosed at least three years after initial treatment; previous endoscopic examination had given either equivocal or negative results in all these three. The importance of the negative findings is, however, uncertain, especially in view of recent reports of an accuracy of only $44 \%$ by radiology and of $58 \%$ by endoscopy for the diagnosis of early gastric cancer. ${ }^{4}$ Even with biopsy, another group ${ }^{5}$ obtained positive histological findings at endoscopy in only four out of nine cases of early gastric cancer. Two of our 12 cases also had a duodenal ulcer, which is generally considered not to be associated with gastric cancer, though the lesions may co-exist. ${ }^{56}$

Although more cases of gastric cancer were seen in the cimetidine group than in the control group, direct comparison between the two groups is misleading because the basis for their initial selection clearly differed-for example, all the treated group were dyspeptics, while few of the controls were. Further differences between the two groups can be seen by comparing the frequency of other complaints. We have noted that those taking cimetidine have tended to have higher rates of hospital consultation and admission for all complaints, digestive and nondigestive, than the controls. ${ }^{1}$ Another (minor) problem arose because of the design of the study. Controls could be selected only after the patients taking cimetidine had been identified and consequently at any single time the total follow-up experience of cimetidine takers is greater than that of the controls, the difference being, on average, about three months. In this report, however, all cases were recorded and then classified according to the timing of the diagnosis of cancer (figure) to minimise this source of non-comparability between the takers and controls.

The means whereby treatment by agents causing intragastric acid neutralisation in general, and cimetidine in particular, could theoretically cause gastric cancer to develop have been discussed elsewhere. ${ }^{7-10}$ Our data are reassuring to the extent that most of the cases described can be explained if treatment had been given to patients with symptoms of undiagnosed malignancy. In a few cases such a clear explanation is not possible. Since, however, the clinical course of gastric cancer is not fully known, some cases-and perhaps all-could still represent cancer that was slowly progressive but diagnosed late, and some random occurrence. We consider these possibilities to be the most likely.

We thank Mrs Margaret Edmond, Mr Tom Lucas, Mrs Maureen Rillie, and Mrs Shirley Wood for their work in conducting the study $\mathrm{Mr}$ John Beresford for help with the computing; Dr A Flind for his help; and the many general practitioners, receptionists, and pharmacists for their enthusiastic co-operation in this project. The study was supported by a grant from Smith, Kline, and French Laboratories Ltd.

\section{References}

1 Colin-Jones DG, Langman MJS, Lawson DH, Vessey MP. Postmarketing surveillance. In: Baron JH, ed Cimetidine in the $80 \mathrm{~s}$. Proceed ings of a symposium at the Royal College of Physicians, March 1981. Edinburgh: Churchill Livingstone, $1981: 270-4$

2 Sakita T. Endoscopy in the diagnosis of early gastric cancer. Clin Gastroenterol $1973 ; 2: 345-60$.

${ }^{3}$ Okabe H. Growth of early gastric cancer. GANN Monograph on Cancer Research 1971;11:67.

4 Green PHR, O'Toole KM, Weinberg LM, Goldfarb JP. Early gastric cancer. Gastroenterology $1981 ; 81: 247-56$.

5 Busuttil A, Webb JN. Early carcinoma of the stomach. $\mathcal{F} R$ Coll Surg Edinb $1981 ; 26: 322-7$.

${ }^{6}$ Ellis DJ, Kingston RD, Brookes VS, Waterhouse JAH. Gastric carcinoma and previous peptic ulceration. Br $\mathcal{F}$ Surg 1979;66:117-9.

${ }^{7}$ Barnard J, Darkin DW, Viney NJ, et al. Effect of cimetidine on twentyfour-hour intragastric $\mathrm{pH}$, bacterial flora, and concentration of nitrite and nitrosocompounds. Gut 1981 ;22:A873.

${ }^{8}$ Elder JB, Ganguli PC, Gillespie IE. Cimetidine and gastric cancer. Lancet 1979;i:1005.

${ }^{9}$ Muscroft TJ, Youngs DJ, Burdon DW, Keighley MR. Cimetidine is unlikely to increase formation of intra-gastric $\mathrm{N}$-nitroso-compounds in patients taking a normal diet. Lancet $1981 ; \mathrm{i}: 408$.

${ }^{10}$ Reed PI, Smith PLR, Haines K, House FR, Walters CL. Effect of cimetidine on gastric juice $\mathrm{N}$-nitrosamine concentration. Lancet 1981; ii :553.

(Accepted 13 August 1982)
GARDEN-RUE is so well known by this name, and the name Herb of Grace, that I shall not need to write any farther description of it, but shall shew you the virtue of it, as follows.

It is an herb of the Sun, and under Leo. It provokes urine and women's courses, being taken either in meat or drink. The seed thereof taken in wine, is an antidote against all dangerous medicines or deadly poisons. The leaves taken either by themselves, or with figs and walnuts, is called Mithridate's counter-poison against the plague, and causes all venomous things to become harmless; being often taken in meat and drink, it abates venery. A decoction thereof with some dried dill leaves and flowers, eases all pains and torments, inwardly to be drank, and outwardly to be applied warm to the place grieved. The same being drank, helps the pains both of the chest and sides, as also coughs and hardness of breathing, the inflammations of the lungs, and the tormenting pains of the sciatica and the joints, being anointed, or laid to the places; as also the shaking fits of agues, to take a draught before the fit comes. Being boiled or infused in oil, it is good to help the wind cholic, the hardness and windiness of the mother, and frees women from the strangling or suffocation thereof, if the share and the parts thereabouts be anointed therewith. It kills and drives forth the worms of the belly, if it be drank after it is boiled in wine to the half, with a little honey; it helps the gout or pains in the joints, hands, feet or knees, applied thereunto; and with figs it helps the dropsy, being bathed therewith: Being bruised and put into the nostrils, it stays the bleeding thereof. It takes away wheals and pimples, if being bruised with a few myrtle leaves, it be made up with wax, and applied. It cures the morphew, and takes away all sorts of warts, if boiled in wine with some pepper and nitre, and the place rubbed therewith, and with almond and honey helps the dry scabs, or any tetter or ringworm. The juice thereof warmed in a pomegranate shell or rind, and dropped into the ears, helps the pains of them. The juice of it and fennel, with a little honey, and the gall of a cock put thereunto, helps the dimness of the eye-sight. An ointment made of the juice thereof with oil of roses, ceruse, and a little vinegar, and anointed, cures St Anthony's fire, and all running sores in the head: and the stinking ulcers of the nose, or other parts. The antidote used by Mithridates, every morning fasting, to secure himself from any poison or infection, was this: Take twenty leaves of rue, a little salt, a couple of walnuts, and a couple of figs, beaten together into a mess, with twenty juniper berries, which is the quantity appointed for every day. Another electuary is made thus: Take of nitre, pepper, and cummin seed, of each equal parts; of the leaves of Rue clean picked, as much in weight as all the other three weighed; beat them well together, and put as much honey as will make it up into an electuary (but you must first steep your cummin seed in vinegar twenty four hours, and then dry it, or rather roast it in a hot fire-shovel, or in an oven) and is a remedy for the pains or griefs in the chest or stomach, of the spleen, belly, or sides, by wind or stitches; of the liver by obstructions; of the reins and bladder by the stopping of urine; and helps also to extentuate fat corpulent bodies. What an infamy is cast upon the ashes of Mithridates, or Methridates (as the Augustines read his name) by unworthy people. They that deserve no good report themselves, love to give none to others, viz That renowned King of Pontus fortified his body by poison against poison. (He cast out devils by Beelzebub, Prince of the devils.) What a sot is he that knows not if he had accustomed his body to cold poisons, but poisons would have dispatched him? on the contrary, if not, corrosions would have done it. The whole world is at this present time beholden to him for his studies in physic, and he that uses the quantity but of an hazel-nut of that receipt every morning, to which his name is adjoined, shall to admiration preserve his body in health, if he do but consider that Rue is an herb of the Sun, and under Leo, and gather it and the rest accordingly. (Nicholas Culpeper (1616-54) The Complete Herbal, 1850.) 